\title{
Microarray analysis of genes with impaired insulin regulation in the skeletal muscle of type 2 diabetic patients indicates the involvement of basic helix-loop-helix domain-containing, class B, 2 protein (BHLHB2)
}

\author{
S. Rome $\cdot$ E. Meugnier $\cdot$ V. Lecomte $\cdot$ V. Berbe $\cdot$ \\ J. Besson • C. Cerutti • S. Pesenti • A. Granjon • \\ E. Disse $\cdot$ K. Clement $\cdot$ E. Lefai $\cdot$ M. Laville $\cdot$ H. Vidal
}

Received: 7 May 2009 / Accepted: 5 June 2009 /Published online: 10 July 2009

(C) Springer-Verlag 2009

\begin{abstract}
Aims/hypothesis One of the major processes by which insulin exerts its multiple biological actions is through gene expression regulation. Thus, the identification of transcription factors affected by insulin in target tissues represents an important challenge. The aim of the present study was to gain a greater insight into this issue through
\end{abstract}

Electronic supplementary material The online version of this article (doi:10.1007/s00125-009-1442-4) contains supplementary material, which is available to authorised users.

S. Rome $(\bowtie) \cdot$ E. Meugnier $\cdot$ V. Lecomte $\cdot$ V. Berbe $\cdot$ J. Besson •

S. Pesenti $\cdot$ A. Granjon $\cdot$ E. Lefai $\cdot$ H. Vidal

INRA 1235, INSERM 870, INSA-Lyon,

Régulations Métaboliques Nutrition et Diabète, Université de Lyon, Oullins 69600, France

e-mail: srome@univ-lyon1.fr

C. Cerutti

INSERM ERI22/EA 4173, Biostatistiques, Université Lyon, Lyon 69008, France

E. Disse $\cdot$ M. Laville

Hospices Civils de Lyon, Service de Diabétologie et Nutrition, Hôpital Edouard-Herriot,

Lyon 69008, France

M. Laville $\cdot$ H. Vidal

Centre de Recherche en Nutrition Humaine Rhône-Alpes,

Oullins 69600, France

K. Clement

Département Nutrition-Métabolisme-Différenciation, INSERM 872, Centre de Recherche des Cordeliers,

Paris 75006, France the identification of transcription factor genes with insulinregulated expression in human skeletal muscle.

Methods Using microarray analysis, we defined the sets of genes modulated during a $3 \mathrm{~h}$ hyperinsulinaemic-euglycaemic clamp $\left(2 \mathrm{mU} \mathrm{min}{ }^{-1} \mathrm{~kg}^{-1}\right)$ in the skeletal muscle of insulin-sensitive control volunteers and in moderately obese insulin-resistant type 2 diabetic patients.

Results Of the 1,529 and 1,499 genes regulated during the clamp in control and diabetic volunteers, respectively, we identified 30 transcription factors with impaired insulinregulation in type 2 diabetic patients. Analysis of the promoters of the genes encoding these factors revealed a possible contribution of the transcriptional repressor basic helix-loop-helix domain-containing, class $\mathrm{B}, 2$ protein (BHLHB2), insulin regulation of which is strongly altered in the muscle of diabetic patients. Gene ontology analysis of BHLHB2 target genes, identified after BHLHB2 overexpression in human primary myotubes, demonstrated that about $10 \%$ of the genes regulated in vivo during hyperinsulinaemia are potentially under the control of this repressor. The data also suggested that BHLHB2 is situated at the crossroads of a complex transcriptional network that is able to modulate major metabolic and biological pathways in skeletal muscle, including the regulation of a cluster of genes involved in muscle development and contraction.

Conclusions/interpretation We have identified BHLHB2 as a potential novel mediator of insulin transcriptional action in human skeletal muscle.

Keywords BHLHB2 - Hyperinsulinaemic-euglycaemic clamp · Insulin · Skeletal muscle · Transcription factors . Transcription network · Type 2 diabetes 


$\begin{array}{ll}\begin{array}{l}\text { Abbreviations } \\ \text { BHLHB2 }\end{array} & \begin{array}{l}\text { Basic helix-loop-helix domain-containing, } \\ \text { class B, 2 }\end{array} \\ \text { CHRE } & \text { Carbohydrate response element } \\ \text { GFP } & \text { Green fluorescent protein } \\ \text { PI3-kinase } & \begin{array}{l}\text { Phosphatidylinositol 3-kinase } \\ \text { SREBP-1c }\end{array} \\ & \begin{array}{l}\text { Sterol regulatory element-binding } \\ \text { transcription factor 1c }\end{array}\end{array}$

\section{Introduction}

Insulin is a pleiotropic hormone that exerts major effects on metabolism and cellular processes, including growth, differentiation and apoptosis. These effects are initiated by specific binding to tyrosine kinase cell surface receptors, which then activate both a metabolic signalling pathway through phosphatidylinositol 3-kinase (PI3-kinase) and a mitogenic pathway through the Ras/mitogen-activated protein kinase cascade [1]. Insulin actions largely result from changes in the activity of enzymes through phosphorylation/dephosphorylation, but it also has major effects through the regulation of a complex pattern of gene expression [2-6]. Up to now, attempts to find a consensus insulin-response element in the promoter sequences of insulin-regulated genes have failed [6], and it is accepted that the effects of insulin on transcription are mediated through the regulation of numerous transcription factors, either by stimulating the transcription of the genes encoding these factors and/or by modifying their cellular location. For instance, sterol regulatory element-binding transcription factor 1c (SREBP-1c) is induced at the mRNA level but also activated by proteolytic cleavage and translocation to the nucleus [7]. Similarly, insulin-response element binding protein-1 (IRE-BP1) is upregulated at the transcriptional level and accumulates in the nucleus in the presence of insulin [8]. These transcription factors have been implicated in the stimulation of gene transcription by insulin. On the other hand, insulin signalling to FoxO1 has been shown to contribute to the repression of gene expression as the result of its nuclear exclusion following insulin stimulation [9].

Despite the fact that insulin modulates the expression of thousands of genes in its target tissues [2-6], very few transcription factors have been described as mediators of insulin action, and the global insulin gene transcription network is far from being completely resolved. To overcome the limitations of classical approaches based on promoter sequence analysis to retrieve potential consensus binding sites in sets of co-regulated genes, a complementary strategy is the consideration of pathological situations in which insulin action is altered, such as in insulinresistance associated with type 2 diabetes. Indeed, a large body of evidence indicates that the transcriptional action of insulin is impaired in insulin resistance [6], and several genes with altered responses to insulin have been identified in the skeletal muscle of type 2 diabetic patients [10-12]. Comparisons of sets of genes with differential regulation between insulin-resistant and insulin-sensitive individuals should thus permit the identification of new key regulatory factors.

Expression profiling is one strategy that can be used to identify sets of genes with altered regulation in response to insulin. Such an approach has been successfully used to identify a cluster of genes with reduced expression levels in the skeletal muscle of type 2 diabetic individuals [13, 14]. Because these genes were collectively involved in the same pathway of oxidative phosphorylation, it was possible to identify common regulatory partners, such as peroxisome proliferator-activated receptor coactivator- $1 \alpha(\mathrm{PGC1} \alpha)$ and nuclear respiratory factor-1 $[13,14]$. However, the volunteers were analysed either in the basal state [13] or after a hyperinsulinaemic clamp [14] only, and so it was not possible to draw any conclusions as to whether the defects in regulation were due to insulin.

We designed the present study to compare the transcriptional effects of insulin in the skeletal muscle of moderately obese insulin-resistant type 2 diabetic patients and agematched insulin-sensitive volunteers during a $3 \mathrm{~h}$ hyperinsulinaemic-euglycaemic clamp [3]. This approach led to the identification of 30 transcription factors with defective regulation by insulin in the muscle of diabetic patients. Among them, special attention was devoted to basic helixloop-helix domain-containing, class $\mathrm{B}$, two protein (BHLHB2; also known as DEC1, SHARP-2 and STRA13) a member of the DEC subfamily of basic helix-loop-helix (bHLH) proteins, which are known to play pivotal roles in multiple pathways [15]. By using a bioinformatic approach, we characterised the role of this factor in the transcriptional action of insulin and in its defective action in the muscle of type 2 diabetic patients.

\section{Methods}

Volunteers and study design All volunteers gave their written consent after being informed of the possible risks of the study, and the protocol was approved by the ethics committee of Hospices Civils de Lyon (Lyon, France). None of the controls had a familial or personal history of diabetes, obesity, dyslipidaemia or hypertension. All the moderately obese type 2 diabetic patients $\left(\mathrm{HbA}_{1 \mathrm{c}} 7.1 \pm\right.$ $0.3 \%$, duration of diabetes $7 \pm 1$ years) were taking metformin as the only oral hyperglycaemic agent. Because metformin treatment did not normalise insulin sensitivity, as estimated by insulin-induced whole body glucose utilisa- 
tion, the treatment was not stopped before the study. After an overnight fast, all volunteers were subjected to a $3 \mathrm{~h}$ euglycaemic-hyperinsulinaemic clamp [16]. Metabolic variables are presented in Table 1. Percutaneous biopsies of the vastus lateralis muscle were taken under local anaesthesia before and after insulin infusion.

Total RNA extraction from muscle samples and microarray analysis Frozen muscle samples were ground in liquid nitrogen, and total RNA was extracted using the classical guanidinium thiocyanate method [16]. The mean yield of total RNA $(0.29 \pm 2 \mu \mathrm{g} / \mathrm{mg}$ of muscle [wet weight]) was not different between groups. Muscle RNA samples were hybridised on cDNA microarrays from the Stanford Functional Genomics Facility (http://www.microarray.org/ sfgf/). The same volunteers were analysed before and after the clamp by using two-colour microarrays [3]. The data sets are available from the GEO database (GSE 11868 and GSE 12844; http://www.ncbi.nlm.nih.gov/geo/, accessed 1 January 2009).

Signal intensities were logarithmically $\left(\log _{e}\right)$ transformed, and normalisation was performed by intensitydependent Lowess method. To compare results from the different experiments, data from each slide were normalised in log space to have a mean of 0 using Cluster 3.0 (http:// rana.lbl.gov/EisenSoftware.htm, accessed 1 January 2009) [3]. Only spots with recorded data on all the slides were selected for further analysis. Using these criteria, 24,024 spots were retrieved, and 10,603 of these had a corresponding gene symbol. Genes with fold changes $\geq 95$ th percentile of genes based on the magnitude of the fold changes in expression between hyperinsulinaemic conditions and basal conditions were considered to be significantly regulated after correction for multiple testing using the Benjamini and Hochberg procedure [17]. With a false discovery rate of $5 \%$, the number of different genes found to be regulated during hyperinsulinaemia was 1,529 in the muscle of the controls (892 up- and 637 downregulated) and 1,499 in the muscle of type 2 diabetic patients (1,279 up- and 220 downregulated).

Analysis of gene promoter sequences One thousand base pairs upstream of transcription starting site of the 30 transcription factors differentially regulated by insulin between healthy volunteers and diabetic patients were retrieved from the Cold Spring Harbor Laboratory mammalian promoter database (CSHLmpd; http://rulai.cshl.edu/cgi-bin/CSHL mpd2/promExtract.pl?species=Human, accessed 1 January 2009). Then, to determine which putative transcription factors could bind these promoter sequences, we used MatInspector from Genomatix (Genomatix Suite release 3.0; Genomatix, Munich, Germany) [18].

Overexpression of BHLHB2 in primary cultures of human skeletal muscle cells A recombinant adenovirus carrying the human BHLHB2 (also known as BHLHE40) coding sequence (GenBank: AB043885.1) was constructed using a previously described procedure [19]. Differentiated myotubes were prepared from skeletal muscle biopsies from four different healthy lean volunteers, as previously described [19]. The cells were infected after 7 days of differentiation in culture medium containing $2 \%$ (vol./vol.) serum, for $48 \mathrm{~h}$ with recombinant adenovirus expressing either the gene encoding green fluorescent protein (GFP) (control) or the gene encoding BHLHB2.

Creatine kinase assay Total protein extracts from BHLHB2and GFP-infected myotubes were used to measure creatine kinase activity by using the CK-NAC LD B kit (ref. no. 1306128) supplied by Sobioda (Montbonnot-Saint-Martin,
Table 1 Metabolic characteristics of the volunteers

${ }^{*} p<0.05,{ }^{* * *} p<0.001$ vs controls

\begin{tabular}{lll}
\hline Variable & Controls $(n=6)$ & Type 2 diabetic patients $(n=6)$ \\
\hline Sex (male/female) & $3 / 3$ & $3 / 3$ \\
Age (years) & $45 \pm 3$ & $49 \pm 3$ \\
BMI $\left(\mathrm{kg} / \mathrm{m}^{2}\right)$ & $23.4 \pm 0.6$ & $30.4 \pm 1.0^{* * *}$ \\
Fasting glucose $(\mathrm{mmol} / \mathrm{l})$ & $4.9 \pm 0.2$ & $7.4 \pm 0.4^{* * *}$ \\
Fasting insulin $(\mathrm{pmol} / \mathrm{l})$ & $40 \pm 6$ & $76 \pm 12^{*}$ \\
NEFA $(\mu \mathrm{mol} / \mathrm{l})$ & $587 \pm 79$ & $484 \pm 44$ \\
Triacylglycerol $(\mu \mathrm{mol} / \mathrm{l})$ & $820 \pm 120$ & $1,277 \pm 250$ \\
Clamp study & & \\
Glucose $(\mathrm{mmol} / \mathrm{l})$ & $4.9 \pm 0.1$ & $5.3 \pm 0.2$ \\
$\quad$ Insulin $(\mathrm{pmol} / \mathrm{l})$ & $1,038 \pm 48$ & $1,104 \pm 42$ \\
Glucose disposal rate $\left(\mathrm{mmol} \mathrm{kg}^{-1} \mathrm{~min}^{-1}\right)$ & $0.0671 \pm 0.0047$ & $0.0308 \pm 0.0054^{* * *}$ \\
Glucose oxidation rate $\left(\mathrm{mmol} \mathrm{kg}^{-1} \mathrm{~min}^{-1}\right)$ & $0.0183 \pm 0.0011$ & $0.0098 \pm 5.3^{*}$ \\
Glucose storage $\left(\mathrm{mmol} \mathrm{kg} \mathrm{min}^{-1}\right)$ & $0.0497 \pm 0.0038$ & $0.0208 \pm 0.0049^{*}$ \\
$\quad$ NEFA $(\mu \mathrm{mol} / \mathrm{l})$ & $38 \pm 3$ & $73 \pm 15^{*}$ \\
\hline
\end{tabular}


France) and assessing enzyme activity spectrophotometrically (wavelength $340 \mathrm{~nm}$ ).

Total RNA extraction from BHLHB2-infected myotubes and microarray analysis Total RNA was extracted with Trizol reagent (Invitrogen Life Technologies, Cergy Pontoise, France). RNA samples were hybridised on RNG/MRC human set 25K microarrays (Réseau National des Génopoles, France; Medical Research Council, UK) produced by the French Genopole Network (25,342 oligonucleotides of 50 -mers printed on glass slides [20]), as previously described [19]. The data set is available from the GEO database (GSE 12947).

Only spots with recorded data on the microarray from the four independent experiments were selected for analysis. Genes with fold changes $\geq 95$ th percentile of genes based on the magnitude of fold changes between BHLHB2and GFP-infected myotubes were considered to be significantly regulated by BHLHB2 after correction for multiple testing using the Benjamini and Hochberg procedure [17]. With a false discovery rate of $5 \%$, we identified 2,079 different genes showing changes in expression levels after BHLHB2 overexpression in human myotubes $(1,309$ upand 770 downregulated).

Quantitative real-time $R T-P C R$ Real-time RT-PCR was performed using ABsolute QPCR SYBR Green ROX Mix (Abgene, Courtaboeuf, France) with a Rotor-Gene 6000 system (Corbett Life Science, Paris, France). Data are expressed as mean \pm SEM. Results were normalised with the gene encoding cyclophilin A (PPIA) used as the reference. Comparisons were analysed using Student's $t$ test. Significance was defined as $p$ value of $<0.05$.

\section{Results}

To study the action of insulin on gene expression in vivo in human skeletal muscle, healthy control volunteers and moderately obese type 2 diabetic volunteers underwent a $3 \mathrm{~h}$ hyperinsulinaemic-euglycaemic clamp. As shown in Table 1, the plasma insulin concentrations reached during the clamp were similar in both groups. Although not physiological, the high concentrations of insulin during the clamp ( $\left.2 \mathrm{mU} \min ^{-1} \mathrm{~kg}^{-1}\right)$ allowed maximal glucose uptake in peripheral tissues, which was seen to be considerably lower in type 2 diabetic patients relative to the controls. This acute hyperinsulinaemia induced during a clamp is a classical method used to study the action of insulin and defective insulin signalling in type 2 diabetic patients [2-4]. Table 1 shows that both non-oxidative glucose disposal and glucose oxidation rates were significantly decreased in moderately obese type 2 diabetic patients during the clamp. They both contributed to the reduction in the insulin-stimulated whole body glucose utilization rate in type 2 diabetic patients, indicating a state of marked insulin resistance.

Skeletal muscle genes regulated during hyperinsulinemic clamp in healthy volunteers and type 2 diabetic patients Microarray analysis led to the identification of 1,529 and 1,499 genes regulated by insulin in the skeletal muscle of controls and type 2 diabetic patients, respectively (Fig. 1). Among them, we noticed that the two groups had only 267 insulin-regulated genes in common, indicating a marked difference in the effect of insulin on muscle gene expression in insulin-sensitive and insulin-resistant individuals. Functional enrichment analyses using FatiGO $^{+}$(http:// babelomics.bioinfo.cipf.es, accessed 1 January 2009) and KEGG (http://www.genome.jp/, accessed 1 January 2009) of the set of 1,499 genes regulated in the insulin-resistant group and the set of 1,529 genes regulated in the control group did not reveal specific functions with altered regulation in the skeletal muscle of the diabetic patients. These results indicated that insulin resistance is associated with profound modifications in the response of the skeletal muscle transcriptome to insulin. To further characterise the actions of insulin on transcription, we then decided to focus on the set of genes encoding transcription factors.

Transcription factors with impaired insulin regulation in type 2 diabetic patients Among the 10,603 genes present on microarrays (see the Methods section), 472 were noted as being for transcription factors in the KEGG database. From this list, we found that 82 transcription factor genes displayed significant changes in their level of expression during the hyperinsulinaemic-euglycemic clamp in the controls (65 up- and 17 downregulated). Among these 82 transcription factors, a cluster of 30 was not regulated in the diabetic patients (Table 2). Because these 30 transcription factor genes showed a coordinated altered response to insulin, we postulated that they could be under the control of common regulatory processes. To identify potential master regulators of their expression, we retrieved the promoter regions of these 30 transcription factor genes and searched for relevant DNA binding motifs for transcription factors in these cis-regulatory sequences. We identified 162 transcription factor-binding sites (also called 'matrix' in Genomatix) (Electronic supplementary material [ESM] Table 1). Interestingly, four binding sites (V\$NFKB, V \$ZNF202, V\$AHRARNT.02 and V\$DEC1.01) corresponded to transcription factor genes present in the list of the 30 with an altered response to hyperinsulinaemia (HIVEP1, ZNF202, ARNT and BHLHB2, respectively) (Table 2). This observation suggested that altered regulation of one or several of these four transcription factors might 
Fig. 1 Summary of the design and sequence of events of the study. T2DM, type 2 diabetes mellitus; TF, transcription factor

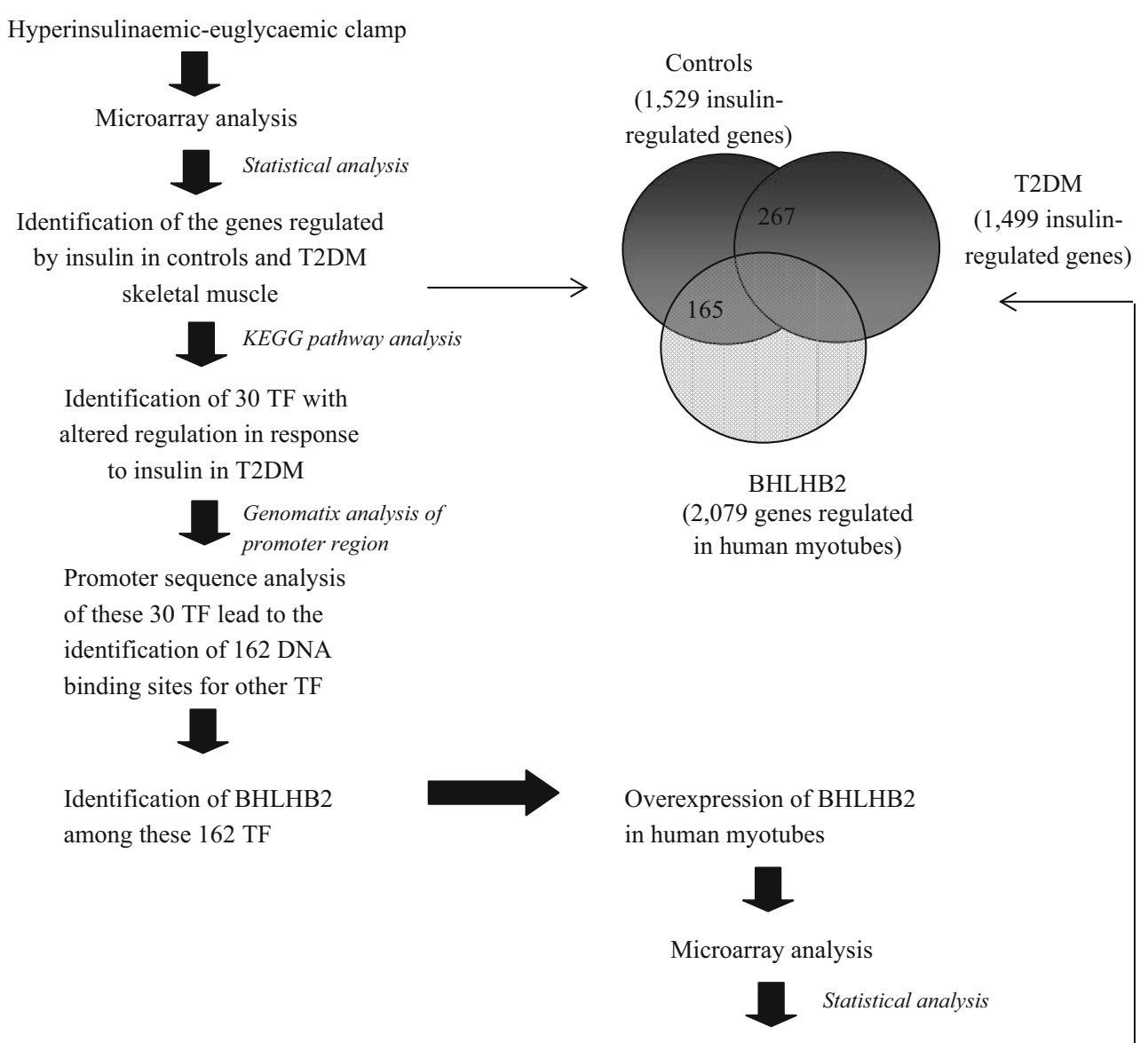

Identification of the genes regulated by BHLHB2 in myotubes lead to the altered regulation of the whole cluster in diabetic patients.

HIVEP1 is known to be involved in immune response [21] but its contribution to insulin action has not been described in the literature. ZNF202 is a transcriptional repressor that is described as a regulator of the expression of genes encoding ATP-binding cassette (ABC) transporter proteins involved in lipid metabolism [22]. However, its direct involvement in mediating the actions of insulin has not yet been reported. In contrast, ARNT is a transcriptional activator that is already suspected to contribute to the actions of insulin on transcription in different cell types [23]. However, its relaxed binding site sequence specificity [24] has until now limited the identification of its target genes. BHLHB2 is a transcriptional repressor. Previous studies have found that BHLHB2 expression is increased by various extracellular stimuli [15], and it was recently reported that insulin could induce BHLHB2 expression in human skeletal muscle [2]. We have also shown that SREBP-1c controls BHLHB2 expression in human muscle cells in culture [19]. Based on these observations and the findings that $B H L H B 2$ possesses a DNA binding site in clearly identified promoter regions (VSDEC1.01 matrix in
Genomatix database) and that this gene displayed the highest fold change in response to hyperinsulinemia in controls (Table 2), we decided to study its involvement in skeletal muscle insulin action in more detail.

The target genes and function of the transcription factor BHLHB2 in human muscle cells We confirmed the insulininduced upregulation of $B H L H B 2$ expression in the muscle of controls by quantitative real-time RT-PCR (1.90-fold increase, $p<0.05)$. In agreement with the microarray results, diabetic patients showed impaired regulation of BHLHB2 expression in response to insulin (1.20-fold increase, $p>$ 0.05 ) (Fig. 2). We used an adenovirus expressing human BHLHB2 combined with oligonucleotide microarrays to determine the target genes of the protein in primary cultures of human muscle cells. We verified the production of BHLHB2 by western blot and estimated that it corresponded to an increase of about fourfold compared with levels under basal conditions (data not shown). Microarray analysis led to the identification of 2,079 mRNAs that showed a significant change in levels following BHLHB2 overexpression (1,309 up- and 770 downregulated) (Fig. 1). Functional analysis of these genes revealed that the 1,309 
Table 2 Transcription factor genes with altered regulation by insulin in skeletal muscle of insulin-resistant type 2 diabetic patients (T2DM)

\begin{tabular}{|c|c|c|c|c|c|c|c|}
\hline \multirow[t]{2}{*}{ LLID } & \multirow[t]{2}{*}{ Symbol } & \multirow[t]{2}{*}{ Name } & \multicolumn{2}{|c|}{ Fold change \pm SEM } & \multirow[t]{2}{*}{$p$ value $^{\mathrm{a}}$} & \multirow[t]{2}{*}{ GO summary function } & \multirow{2}{*}{$\begin{array}{l}\text { DNA binding } \\
\text { motif specificity } \\
\text { (Genomatix) }\end{array}$} \\
\hline & & & Controls & $\begin{array}{l}\text { T2DM } \\
\text { patients }\end{array}$ & & & \\
\hline 405 & $A R N T^{\mathrm{b}}$ & $\begin{array}{l}\text { Aryl hydrocarbon receptor } \\
\text { nuclear translocator }\end{array}$ & $1.2 \pm 0.07$ & $0.85 \pm 0.06$ & 0.0019 & $\begin{array}{l}\text { Adaptative response } \\
\text { to hypoxia/CLOCK } \\
\text { gene }\end{array}$ & $\begin{array}{l}\text { V\$HIFF and } \\
\text { V\$AHRR }\end{array}$ \\
\hline 429 & $A S C L 1$ & $\begin{array}{l}\text { Achaete-scute complex } \\
\text { homologue } 1 \text { (Drosophila) }\end{array}$ & $1.2 \pm 0.04$ & $0.95 \pm 0.06$ & 0.0095 & $\begin{array}{l}\text { Notch signalling } \\
\text { pathway/nervous } \\
\text { system development }\end{array}$ & V\$MYOD \\
\hline 8553 & BHLHB2 & $\begin{array}{l}\text { Basic helix-loop-helix } \\
\text { domain containing, } \\
\text { class B, } 2\end{array}$ & $1.66 \pm 0.17$ & $1.09 \pm 0.03$ & 0.0196 & $\begin{array}{l}\text { Control of cell } \\
\text { differentiation/adaptative } \\
\text { response to hypoxia/ } \\
\text { CLOCK gene }\end{array}$ & V\$HESF \\
\hline 3607 & $F O X K 2$ & Forkhead box K2 & $1.26 \pm 0.11$ & $0.91 \pm 0.27$ & 0.0304 & & V\$FKHD \\
\hline 140628 & GATA5 & GATA binding protein 5 & $1.26 \pm 0.06$ & $0.88 \pm 0.07$ & 0.0036 & Muscle development & V\$GATA \\
\hline 2736 & GLI2 & $\begin{array}{l}\text { GLI-Kruppel family } \\
\text { member GLI2 }\end{array}$ & $1.20 \pm 0.06$ & $0.79 \pm 0.06$ & 0.0015 & $\begin{array}{l}\text { Hedgehog signalling/ } \\
\text { myogenesis }\end{array}$ & V\$GFI1 \\
\hline 8328 & GFIIB & $\begin{array}{l}\text { Growth factor independent } \\
1 \mathrm{~B} \text { transcription repressor }\end{array}$ & $1.30 \pm 0.08$ & $0.78 \pm 0.06$ & 0.0011 & $\begin{array}{l}\text { Regulator of erythroid } \\
\text { and megakaryocyte } \\
\text { development }\end{array}$ & V\$GFI1 \\
\hline 3159 & $H M G A 1$ & $\begin{array}{l}\text { High mobility group } \\
\text { AT-hook } 1\end{array}$ & $1.21 \pm 0.08$ & $0.91 \pm 0.007$ & 0.0206 & $\begin{array}{l}\text { Regulation of insulin } \\
\text { receptor activity }\end{array}$ & V\$SORY \\
\hline 3096 & HIVEP1 & $\begin{array}{l}\text { Human immunodeficiency } \\
\text { virus type I enhancer } \\
\text { binding protein } 1\end{array}$ & $1.22 \pm 0.04$ & $0.91 \pm 0.10$ & 0.0322 & Apoptosis & V\$NFKB \\
\hline 4807 & NHLH1 & Nescient helix-loop-helix 1 & $1.19 \pm 0.06$ & $0.72 \pm 0.08$ & 0.0012 & $\begin{array}{l}\text { Regulation of body } \\
\text { weight metabolism }\end{array}$ & V\$HAND \\
\hline 4775 & NFATC3 & $\begin{array}{l}\text { Nuclear factor of activated } \\
\text { T cells, cytoplasmic, } \\
\text { calcineurin-dependent } 3\end{array}$ & $1.25 \pm 0.09$ & $0.80 \pm 0.07$ & 0.0019 & Muscle development & V\$NFAT \\
\hline 4782 & NFIC & $\begin{array}{l}\text { Nuclear factor I/C } \\
\text { (CCAAT-binding } \\
\text { transcription factor) }\end{array}$ & $1.20 \pm 0.07$ & $0.75 \pm 0.07$ & 0.0005 & $\begin{array}{l}\text { Negative sensor of } \\
\text { oxidative stress }\end{array}$ & V\$NF1F \\
\hline 8648 & NCOA1 & $\begin{array}{l}\text { Nuclear receptor } \\
\text { coactivator } 1\end{array}$ & $1.37 \pm 0.19$ & $0.81 \pm 0.03$ & 0.0355 & Lipid metabolism & \\
\hline 6939 & TCF 15 & $\begin{array}{l}\text { Transcription factor } 15 \\
\text { (basic helix-loop-helix) }\end{array}$ & $1.24 \pm 0.07$ & $0.80 \pm 0.06$ & 0.0011 & Muscle development & V\$HAND \\
\hline 7027 & $T F D P 1$ & Transcription factor Dp-1 & $1.29 \pm 0.03$ & $0.90 \pm 0.02$ & 0.0189 & Muscle development & V\$E2FF \\
\hline 5966 & $R E L$ & $\begin{array}{l}\text { V-rel reticuloendotheliosis } \\
\text { viral oncogene homologue } \\
\text { (avian) }\end{array}$ & $1.4 \pm 0.07$ & $0.98 \pm 0.11$ & 0.0135 & $\begin{array}{l}\text { Cytokine production/ } \\
\text { nuclear factor } \mathrm{kB} \\
\text { cascade }\end{array}$ & ND \\
\hline 342945 & ZSCAN22 & $\begin{array}{l}\text { Zinc finger and SCAN } \\
\text { domain containing } 22\end{array}$ & $1.48 \pm 0.3$ & $0.65 \pm 0.04$ & 0.0400 & & ND \\
\hline 6935 & $Z E B 1$ & $\begin{array}{l}\text { Zinc finger E-box } \\
\text { binding homeobox } 1\end{array}$ & $1.24 \pm 0.12$ & $0.87 \pm 0.08$ & 0.0411 & Muscle development & V\$ZFHX \\
\hline 284307 & $Z I K 1$ & $\begin{array}{l}\text { Zinc finger protein } \\
\text { interacting with } \mathrm{K} \\
\text { protein } 1 \text { homologue }\end{array}$ & $1.20 \pm 0.04$ & $0.81 \pm 0.17$ & 0.0002 & & ND \\
\hline 7743 & ZNF189 & Zinc finger protein 189 & $1.49 \pm 0.08$ & $1.09 \pm 0,07$ & 0.0056 & & ND \\
\hline 7753 & ZNF202 & Zinc finger protein 202 & $1.20 \pm 0.07$ & $0.78 \pm 0.16$ & 0.008 & Lipid metabolism & V\$ZBPF \\
\hline 10127 & ZNF263 & Zinc finger protein 263 & $1.34 \pm 0.08$ & $1.00 \pm 0.06$ & 0.0096 & & ND \\
\hline 1628 & $D B P$ & $\begin{array}{l}\text { D site of albumin } \\
\text { promoter (albumin D-box) } \\
\text { binding protein }\end{array}$ & $0.64 \pm 0.05$ & $0.87 \pm 0.07$ & 0.0313 & & V\$PARF \\
\hline 2099 & ESRl & Oestrogen receptor 1 & $0.77 \pm 0.05$ & $1.04 \pm 0.06$ & 0.0069 & $\begin{array}{l}\text { Nitric-oxide synthase } \\
\text { regulatory activity }\end{array}$ & V\$EREF \\
\hline 2309 & $\mathrm{FOXO3}$ & Forkhead box $\mathrm{O} 3$ & $0.75 \pm 0.02$ & $1.03 \pm 0.06$ & 0.0227 & $\begin{array}{l}\text { Muscle development/ } \\
\text { energy metabolism/ } \\
\text { insulin signalling }\end{array}$ & V\$FKHD \\
\hline
\end{tabular}


Table 2 (continued)

\begin{tabular}{|c|c|c|c|c|c|c|c|}
\hline \multirow[t]{2}{*}{ LLID } & \multirow[t]{2}{*}{ Symbol } & \multirow[t]{2}{*}{ Name } & \multicolumn{2}{|c|}{ Fold change \pm SEM } & \multirow[t]{2}{*}{$p$ value $^{\mathrm{a}}$} & \multirow[t]{2}{*}{ GO summary function } & \multirow{2}{*}{$\begin{array}{l}\text { DNA binding } \\
\text { motif specificity } \\
\text { (Genomatix) }\end{array}$} \\
\hline & & & Controls & $\begin{array}{l}\text { T2DM } \\
\text { patients }\end{array}$ & & & \\
\hline 4781 & $N F I B$ & Nuclear factor I/B & $0.70 \pm 0.01$ & $1.03 \pm 0.11$ & 0.0010 & $\begin{array}{l}\text { Negative regulation } \\
\text { of Notch signalling } \\
\text { pathway/development }\end{array}$ & V\$NF1F \\
\hline 4792 & NFKBIA & $\begin{array}{l}\text { Nuclear factor of } \mathrm{k} \\
\text { light polypeptide } \\
\text { gene enhancer in } \mathrm{B} \\
\text { cells inhibitor, } \alpha\end{array}$ & $0.57 \pm 0.04$ & $0.73 \pm 0.08$ & 0.0457 & $\begin{array}{l}\text { Notch signalling } \\
\text { pathway }\end{array}$ & ND \\
\hline 5308 & PITX2 & Paired-like homeodomain 2 & $0.8 \pm 0.03$ & $1.01 \pm 0.11$ & 0.0453 & Muscle development & V\$BCDF \\
\hline 7068 & $T H R B$ & $\begin{array}{l}\text { Thyroid hormone receptor, } \\
\text { beta (erythroblastic } \\
\text { leukaemia viral (v-erb-a) } \\
\text { oncogene homologue } 2 \text {, } \\
\text { avian) }\end{array}$ & $0.76 \pm 0.02$ & $1.04 \pm 0.11$ & 0.0152 & $\begin{array}{l}\text { Steroid hormone } \\
\text { receptor activity/ } \\
\text { regulation of heart } \\
\text { contraction }\end{array}$ & V\$RXRF \\
\hline 7594 & ZNF43 & Zinc finger protein 43 & $0.84 \pm 0.02$ & $0.92 \pm 0.13$ & 0.0370 & & ND \\
\hline
\end{tabular}

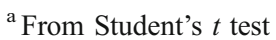

${ }^{\mathrm{b}}$ Also known as $H I F 1 B$

GO, Gene Ontology from Babelomics; LLID, Locus Link Gene ID; ND, not determined

upregulated genes were significantly enriched with genes related to transcription, translation (ribosome) or RNA synthesis, whereas the 770 downregulated genes were enriched with genes encoding proteins involved in muscle functions (contraction and development), which are mostly located in cytoskeleton and myofibrils (ESM Table 2).

Because the forced expression of BHLHB2 could have resulted in indirect regulation, we further limited the analysis to the direct target genes of BHLHB2 by selecting those with V\$DEC1.01 matrix in their promoter sequence (BHLHB2 DNA binding motif in Genomatix). Among the 2,079 genes regulated in myotubes overexpressing BHLHB2, 1,647 had a promoter sequence available in promoter databases. Using Genomatix, we found that only $1.6 \%$ of the upregulated genes displayed at least one V\$DEC1.01 motif in their promoter sequence while about 22\% (125 genes) of the downregulated genes could be considered as direct target genes of BHLHB2. This result was in agreement with the known transcriptional repressor function of BHLHB2 [15, 25]. This also indicated that the majority of the upregulated genes were probably upregulated as a result of indirect effects of forced BHLHB2 production. The 125 downregulated genes with a V\$DEC1.01 motif in their promoter region encoded cytoskeleton structural proteins and proteins involved in regulating transcription and translation (ESM Table 3).

To determine whether BHLHB2 could be involved in the control of muscle functions, we measured creatine kinase activity in differentiated human myotubes expressing either the gene encoding BHLHB2 or the gene encoding GFP (control).
As shown in Fig. 3, creatine kinase activity was reduced in the presence of BHLHB2. This result is in agreement with an expected decreased of muscle cell energy status upon BHLHB2 expression, as suggested by microarray results indicating the downregulation of several muscle-specific genes.

Implication of BHLHB2 in the effects of insulin on transcription in skeletal muscle Among the 2,079 genes affected by the overexpression of BHLHB2 in muscle cells, 165 genes were also included in the set of 1,529 genes regulated in the skeletal muscle of the controls, thus representing more than $10 \%$ of the genes regulated during hyperinsulinaemia. This result suggested that a significant proportion of the actions of insulin on transcription in human muscle could involve the transcription factor BHLHB2. Investigation of the genes regulated in the muscle of diabetic patients revealed a subset of 31 genes that also appeared in the list of BHLHB2-regulated genes (Table 3). Two of these contained V\$DEC1.01 motifs and could be considered to be direct targets of BHLHB2. These encoded HIVEP1, which is present in the list of transcription factors with altered regulation in response to insulin in type 2 diabetic patients (Table 2), and SLC5A3, an osmoprotective protein [26].

\section{Discussion}

In agreement with previous reports [2-4], the results from our microarray data analysis confirmed major effects of insulin on gene expression in human skeletal muscle in 


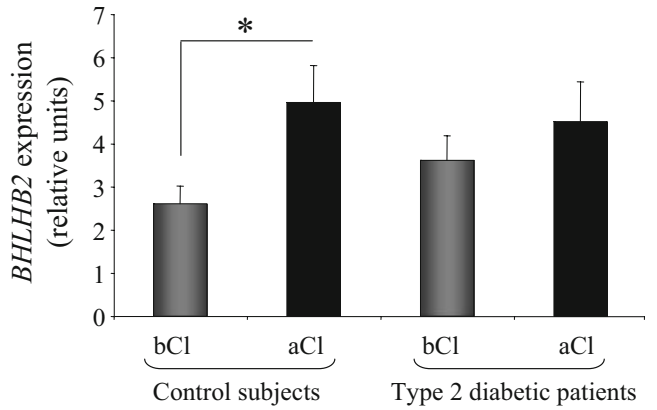

Fig. 2 Fold change of $B H L H B 2$ expression in the skeletal muscle of insulin-sensitive volunteers or insulin-resistant type 2 diabetic patients before $(\mathrm{bCl})$ or after $(\mathrm{aCl})$ a $3 \mathrm{~h}$ hypersinsulinaemic-euglycaemic clamp. Fold changes are expressed as relative units. ${ }^{*} p<0.05$ using the paired Student's $t$ test

vivo. The affected genes encoded proteins involved in almost all cellular functions, in agreement with the wide spectrum of actions of insulin [3]. We also observed that insulin resistance in moderately obese type 2 diabetic patients was associated with a profound disorganisation of the pattern of genes normally regulated during hyperinsulinaemia. Over the last decade, several studies have identified altered insulin regulation in the muscle of type 2 diabetic patients. However, only a limited number of candidate genes have been studied [10-12, 27, 28]. Using large-scale analysis we found that more than $80 \%$ of the regulated genes in the muscle of healthy individuals displayed an impaired insulin response in the muscle of type 2 diabetic patients. This global modification indicates that the altered regulation of gene expression by insulin is certainly not a consequence of a specific defect at the level of a given transcription factor, but, rather, the result of upstream alterations in insulin action. This conclusion is consistent with the currently accepted cause of insulin resistance in type 2 diabetes involving defective phosphorylation of IRS-1 [29-31]. Such an alteration of the first step of the insulin signalling cascade probably modifies the regulation of several transcription factors and drastically changes the pattern of gene expression during hyperinsulinaemia. However, it should be mentioned that the effect of obesity-related insulin resistance, in addition to diabetes, could have also contributed to the findings. Of note, the regulation of 267 genes was not affected, and these genes displayed a similar response in the muscle of insulin-sensitive and insulin-resistant individuals. These genes could be regulated by a pathway independent from the altered insulin signalling pathway, or, more likely, could be controlled by variables other than hyperinsulinaemia during the clamp.

When focusing on the transcription factors that were regulated during hyperinsulinaemia in the control group but not in the insulin-resistant patients, we identified a subset of 30 genes with an impaired response. Interestingly, two of them (ESRI and NFKBIA) have previously been associated with type 2 diabetes and insulin resistance traits in genetic studies [32,33], and individuals with defective HMGA1 expression showed decreased insulin receptor levels and a diabetic phenotype [34]. Thus, the altered regulation of the expression of these genes by insulin may contribute to the pathology. With the aim of furthering our understanding of the molecular causes of the deregulation of the expression of these 30 genes, we analysed the presence of potential binding sites for regulatory factors in their promoter regions. Among the potential candidates, we decided to focus on BHLHB2, a transcriptional repressor that plays pivotal roles in multiple signalling pathways that affect many biological processes, including development, cell differentiation, cell growth, cell death, oncogenesis, immune systems and circadian rhythm [15]. In view of the multiple biological actions of insulin, these observations strongly suggested BHLHB2 as one of the possible mediators of the effects of insulin. In line with this, a recent report showed that BHLHB2 inhibits the expression of insulin-induced lipogenic genes by inhibiting the binding of carbohydrate response element-binding protein to the carbohydrate response element of the FASN gene promoter [35]. Moreover, its expression is strongly increased in the liver of $o b / o b$ mice and in mice fed a high-fat diet [35]. Furthermore, BHLHB2 shows the highest fold change in expression in response to insulin in the muscle of controls (Table 2), and its induction during the clamp was clearly validated using quantitative real-time RT-PCR. Finally, its DNA binding site is well-described in the databases, allowing prediction of its potential targets in the lists of genes obtained by microarray in the muscle of the two groups of volunteers.

To determine the contribution of BHLHB2 to the effects of insulin on transcription, we overexpressed the gene for this transcription factor in differentiated human myotubes using an adenoviral vector. Microarray analysis of the transcriptional changes induced by BHLHB2 revealed that about $10 \%$ of the genes regulated in vivo during hyperinsulinaemia in the skeletal muscle of healthy individuals

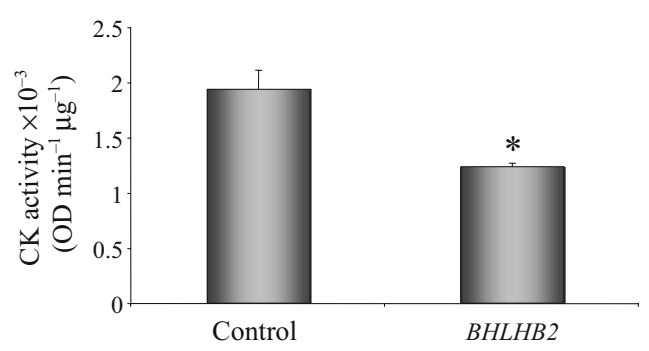

Fig. 3 Creatine kinase activity in human myotubes overexpressing BHLHB2 or the gene encoding GFP (control). ${ }^{*} p<0.05$ using the paired Student's $t$ test 


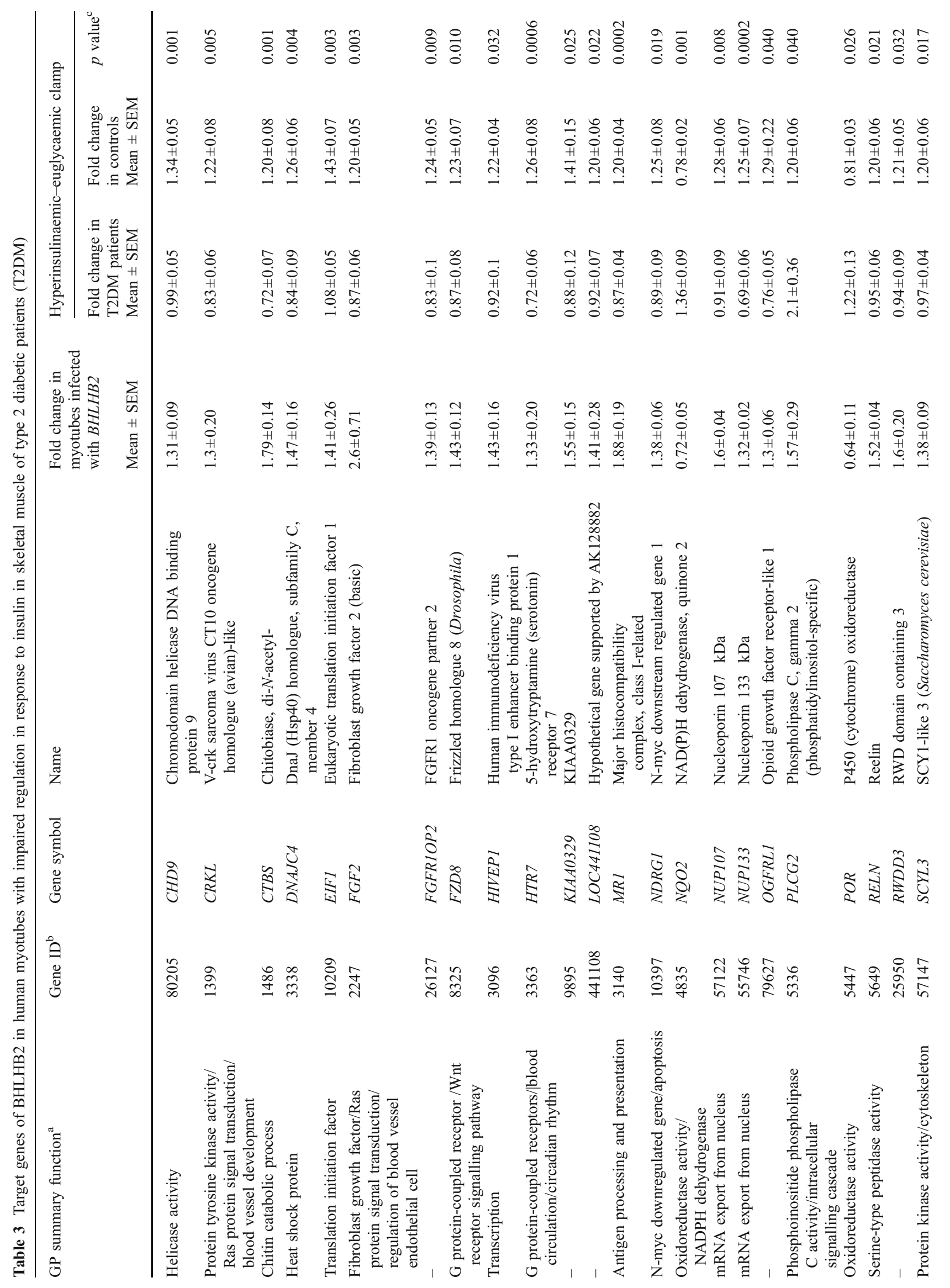




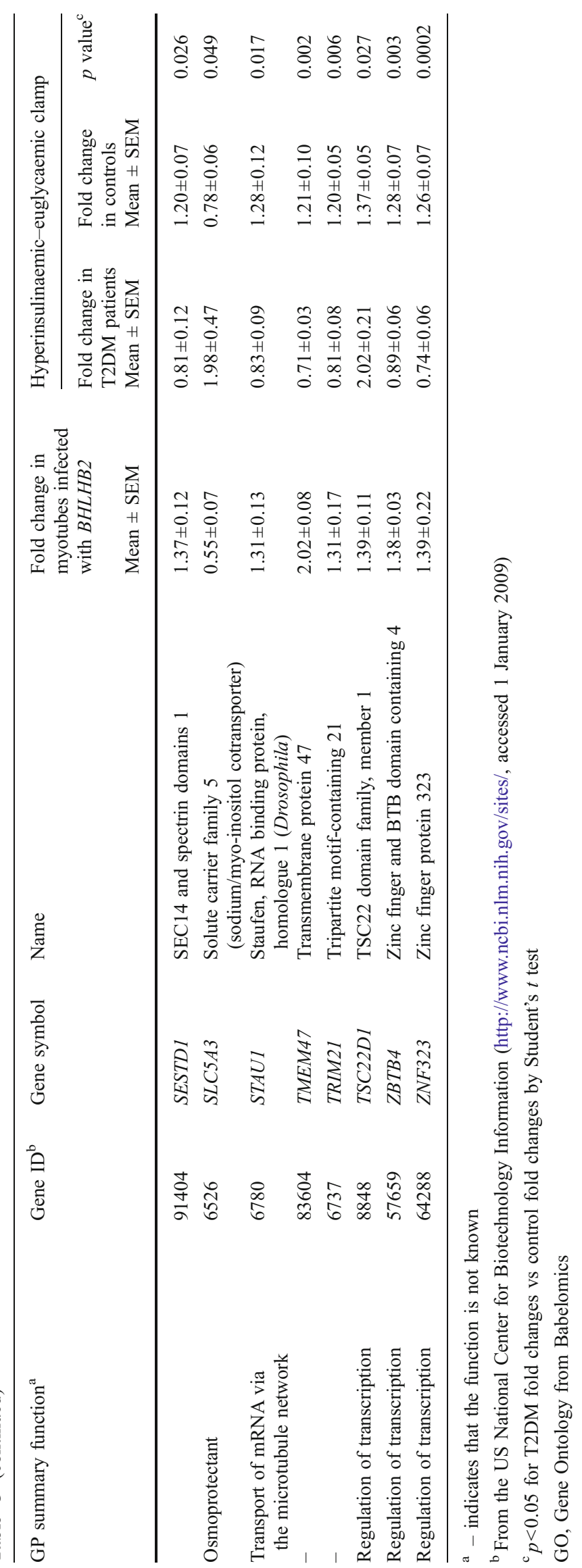




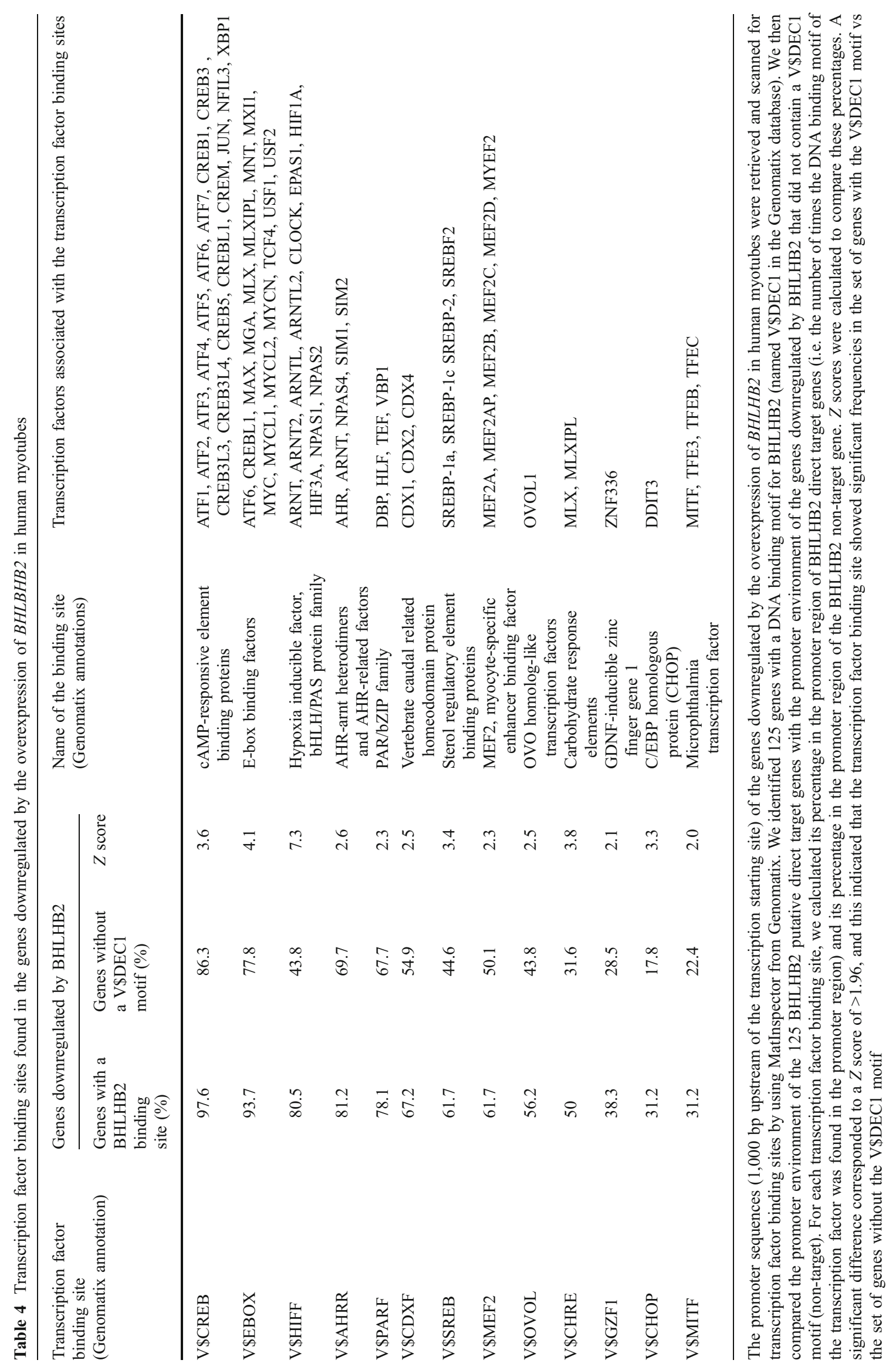


are also regulated by $B H L H B 2$ overexpression in human muscle cells, suggesting a possible contribution of this transcription factor in insulin action. As in our study, a recent report showed that BHLHB2 expression is induced by insulin in human muscle [2]. Although this remains to be demonstrated in muscle, this effect of insulin on BHLHB2 expression is likely to be mediated through the activation of the PI3-kinase pathway, as evidenced in rat liver [36]. Under such conditions, the impaired regulation of $B H L H B 2$ expression in type 2 diabetic patients might certainly be a consequence of the well-demonstrated defective activation of this signalling pathway in response to hyperinsulinaemia in the skeletal muscle of these patients $[29,30,37]$.

Promoter analysis of the 125 genes with binding sites for BHLHB2 revealed that there was a significant association between the presence of binding sites for BHLHB2 and the presence of DNA binding sites for several other transcription factors (Table 4). Interestingly, recent observations showed possible interactions between BHLHB2 and the carbohydrate response element (CHRE motif) in the promoter regions of key genes involved in lipogenesis in the liver [35], suggesting an unexpected role of BHLHB2 in the regulation of metabolism [35]. In agreement with this, we found that half of the 125 BHLHB2 target genes also contained CHRE motifs (V\$CHRE in Table 4), including the gene coding 1-pyruvate kinase (ESM Table 3). In addition, more than $60 \%$ of genes directly targeted by BHLHB2 also had putative sterol regulatory element (SRE) motifs for transcription factors related to the SREBP family (V\$SREB in Table 4). SREBP proteins are transcriptional activators involved in lipid metabolism and are strongly activated by insulin in vitro and in vivo [7, 11]. The interplay between SREBP-1 and BHLHB2 is also supported by recent data showing a remarkable increase in BHLHB2 mRNA levels in human myotubes $[19,35]$ and in mouse hepatocytes [35] following SREBP-1 (also known as $S R E B F 1)$ overexpression. Furthermore, under hypoxic conditions, BHLHB2 appeared to repress the expression of SREBF1, a major mediator of insulin action [7], hence contributing to the repression of lipogenesis and ATP generation to protect cells from the risk of energy failure [38]. The recent literature suggests a possible role for BHLHB2 in the control of lipid metabolism and lipogenesis in the liver of rodents [35]. Taken together, these data suggest that BHLHB2 could be a novel mediator of the regulatory effects of insulin on glucose and lipid metabolism. Further studies are now needed to verify this hypothesis, especially in human tissues. In humans, Coletta et al. recently reported an increased BHLHB2 mRNA levels in the muscle of non-obese type 2 diabetic patients [2]. We also noted a tendency for an increased expression in the muscle of the obese type 2 diabetic patients included in this study, but the difference did not reach significance (Fig. 2).

Finally, we found that genes that had their expression downregulated by BHLHB2 showed significant enrichment of myocyte-specific enhancer binding factor binding sites, which bind major transcription factors involved in muscle development [39] (V\$MEF2 motifs in Table 4). This is consistent with the downregulation of several musclespecific markers in myotubes overexpressing BHLHB2. In agreement with this observation, we found that increased levels of BHLHB2 in human myotubes promoted a significant decrease in creatine kinase activity. This also suggests that the impaired regulation of BHLHB2 expression observed in insulin-resistant patients may be associated with altered levels of creatine kinase activity in muscle, a situation that characterises low energy status and mitochondrial dysfunction, as classically observed in type 2 diabetes [40]. Furthermore, recent observations indicate that, in addition to decreased levels of mitochondria, type 2 diabetes is also associated with structural changes in skeletal muscle, including signs of muscle atrophy and decreased muscle fibre transformation [41]. Taken together, these data support the hypothesis that impaired regulation of BHLHB2 contributes to these structural defects in the skeletal muscle of the diabetic patients.

Insulin action on transcription in skeletal muscle induces a complex pattern of gene expression that is poorly described. Our strategy, based on the comparison of two physiological situations (insulin-sensitivity vs insulinresistance) using microarrays permitted the identification major alterations in gene expression during hyperinsulinaemia in the muscle of moderately obese type 2 diabetic patients and the identification of 30 transcription factors with impaired insulin regulation. Among them, BHLHB2 is a potential novel mediator of the effects of insulin on transcription, and we found that $10 \%$ of the genes regulated by insulin in controls are potentially under its control. We further documented its deregulation in response to hyperinsulinaemia in the skeletal muscle of type 2 diabetic patients. Taken together, these data clearly show that BHLHB2 is an interesting and relevant mediator of insulin actions and of defective insulin signalling in type 2 diabetes.

Acknowledgements The authors thank E. Loizon and N. Vega for RNA extractions; C. Picat and C. Debard for human muscle cell culture; J. Vouillarmet for skeletal muscle biopsies; and J Delarichaudy for creatine kinase activity quantification (all at INRA 1235, INSERM 870, INSA-Lyon, Régulations Métaboliques Nutrition et Diabète, Université de Lyon, Oullins, France). This work was supported by research grants from INSERM (ATC-nutrition $\left.n^{\circ} 4 \mathrm{NU} 10 \mathrm{G}\right)$, INRA, Inter-EPST Bioinformatic Program, EZUS-Lyon1, Région RhôneAlpes, Institut de Recherche Servier, ALFEDIAM-Roche and La Fondation Claude Bernard. 
Duality of interest The authors declare that there is no duality of interest associated with this manuscript.

\section{References}

1. Virkamaki A, Ueki K, Kahn CR (1999) Protein-protein interaction in insulin signaling and the molecular mechanisms of insulin resistance. J Clin Invest 103:931-943

2. Coletta DK, Balas B, Chavez AO et al (2008) Effect of acute physiological hyperinsulinemia on gene expression in human skeletal muscle in vivo. Am J Physiol 294:E910-E917

3. Rome S, Clement K, Rabasa-Lhoret R et al (2003) Microarray profiling of human skeletal muscle reveals that insulin regulates approximately 800 genes during a hyperinsulinemic clamp. J Biol Chem 278:18063-18068

4. Wu X, Wang J, Cui X et al (2007) The effect of insulin on expression of genes and biochemical pathways in human skeletal muscle. Endocrine 31:5-17

5. Jee S, Hwang D, Seo S et al (2007) Microarray analysis of insulin-regulated gene expression in the liver: the use of transgenic mice co-expressing insulin-siRNA and human IDE as an animal model. Int J Mol Med 20:829-835

6. O'Brien RM, Granner DK (1996) Regulation of gene expression by insulin. Physiol Rev 76:1109-1161

7. Osborne TF (2000) Sterol regulatory element-binding proteins (SREBPs): key regulators of nutritional homeostasis and insulin action. J Biol Chem 275:32379-32382

8. Chahal J, Chen CC, Rane MJ et al (2008) Regulation of insulinresponse element binding protein- 1 in obesity and diabetes: potential role in impaired insulin-induced gene transcription. Endocrinology 149:4829-4836

9. Barthel A, Schmoll D, Unterman TG (2005) FoxO proteins in insulin action and metabolism. Trends Endocrinol Metab 16:183-189

10. Andersen PH, Lund S, Vestergaard H, Junker S, Kahn BB, Pedersen O (1993) Expression of the major insulin regulatable glucose transporter (GLUT4) in skeletal muscle of noninsulindependent diabetic patients and healthy subjects before and after insulin infusion. J Clin Endocrinol Metab 77:27-32

11. Ducluzeau PH, Perretti N, Laville M et al (2001) Regulation by insulin of gene expression in human skeletal muscle and adipose tissue. Evidence for specific defects in type 2 diabetes. Diabetes 50:1134-1142

12. Vestergaard H, Bjorbaek C, Hansen T, Larsen FS, Granner DK, Pedersen O (1995) Impaired activity and gene expression of hexokinase II in muscle from non-insulin-dependent diabetes mellitus patients. J Clin Invest 96:2639-2645

13. Patti ME, Butte AJ, Crunkhorn S et al (2003) Coordinated reduction of genes of oxidative metabolism in humans with insulin resistance and diabetes: potential role of $P G C 1$ and NRF1. Proc Natl Acad Sci U S A 100:8466-8471

14. Mootha VK, Lindgren CM, Eriksson KF et al (2003) PGC1alpha-responsive genes involved in oxidative phosphorylation are coordinately downregulated in human diabetes. Nat Genet 34:267-273

15. Yamada K, Miyamoto K (2005) Basic helix-loop-helix transcription factors, BHLHB2 and BHLHB3; their gene expressions are regulated by multiple extracellular stimuli. Front Biosci 10:31513171

16. Laville M, Auboeuf D, Khalfallah Y, Vega N, Riou JP, Vidal H (1996) Acute regulation by insulin of phosphatidylinositol-3kinase, Rad, Glut 4, and lipoprotein lipase mRNA levels in human muscle. J Clin Invest 98:43-49
17. Benjamini Y, Hochberg Y (1995) Controlling the false discovery rate: a practical and powerful approach to multiple testing. J R Stat Soc: Ser B (Methodol) 57:289-300

18. Cartharius K, Frech K, Grote K et al (2005) MatInspector and beyond: promoter analysis based on transcription factor binding sites. Bioinformatics (Oxford, England) 21:2933-2942

19. Rome S, Lecomte V, Meugnier E et al (2008) Microarrays analysis of SREBP-1a and SREBP-1c target genes identify new regulatory pathways in muscle. Physiol Genomics 34:327-337

20. Le Brigand K, Russell R, Moreilhon C et al (2006) An openaccess long oligonucleotide microarray resource for analysis of the human and mouse transcriptomes. Nucleic Acids Res 34:e87

21. Nomura N, Zhao MJ, Nagase T et al (1991) HIV-EP2, a new member of the gene family encoding the human immunodeficiency virus type 1 enhancer-binding protein. Comparison with HIVEP1/PRDII-BF1/MBP-1. J Biol Chem 266:8590-8594

22. Schmitz G, Langmann T (2005) Transcriptional regulatory networks in lipid metabolism control ABCA1 expression. Biochim Biophys Acta 1735:1-19

23. Zelzer E, Levy Y, Kahana C, Shilo BZ, Rubinstein M, Cohen B (1998) Insulin induces transcription of target genes through the hypoxia-inducible factor HIF-1alpha/ARNT. EMBO J 17:50855094

24. Swanson HI, Chan WK, Bradfield CA (1995) DNA binding specificities and pairing rules of the Ah receptor, ARNT, and SIM proteins. J Biol Chem 270:26292-26302

25. St-Pierre B, Flock G, Zacksenhaus E, Egan SE (2002) Stra13 homodimers repress transcription through class B E-box elements. J Biol Chem 277:46544-46551

26. Klaus F, Palmada M, Lindner R et al (2008) Up-regulation of hypertonicity-activated myo-inositol transporter SMIT1 by the cell volume-sensitive protein kinase SGK1. J Physiol 586:15391547

27. Pendergrass M, Koval J, Vogt C et al (1998) Insulin-induced hexokinase II expression is reduced in obesity and NIDDM. Diabetes 47:387-394

28. Andreelli F, Laville M, Ducluzeau PH et al (1999) Defective regulation of phosphatidylinositol-3-kinase gene expression in skeletal muscle and adipose tissue of non-insulin-dependent diabetes mellitus patients. Diabetologia 42:358-364

29. Frojdo S, Vidal H, Pirola L (2009) Alterations of insulin signaling in type 2 diabetes: a review of the current evidence from humans. Biochim Biophys Acta 1792:83-92

30. Bouzakri K, Roques M, Gual P et al (2003) Reduced activation of phosphatidylinositol-3 kinase and increased serine 636 phosphorylation of insulin receptor substrate-1 in primary culture of skeletal muscle cells from patients with type 2 diabetes. Diabetes 52:1319-1325

31. Draznin B (2006) Molecular mechanisms of insulin resistance: serine phosphorylation of insulin receptor substrate-1 and increased expression of p85alpha: the two sides of a coin. Diabetes 55:2392-2397

32. Dahlman I, Vaxillaire M, Nilsson M et al (2008) Estrogen receptor alpha gene variants associate with type 2 diabetes and fasting plasma glucose. Pharmacogenet Genomics 18:967-975

33. Romzova M, Hohenadel D, Kolostova K et al (2006) NFkappaB and its inhibitor IkappaB in relation to type 2 diabetes and its microvascular and atherosclerotic complications. Hum Immunol 67:706-713

34. Foti D, Chiefari E, Fedele M et al (2005) Lack of the architectural factor HMGA1 causes insulin resistance and diabetes in humans and mice. Nat Med 11:765-773

35. Iizuka K, Horikawa Y (2008) Regulation of lipogenesis via BHLHB2/DEC1 and ChREBP feedback looping. Biochem Biophys Res Commun 374:95-100 
36. Yamada K, Kawata H, Shou Z, Mizutani T, Noguchi T, Miyamoto $\mathrm{K}$ (2003) Insulin induces the expression of the SHARP-2/Stra13/ $D E C 1$ gene via a phosphoinositide 3-kinase pathway. J Biol Chem 278:30719-30724

37. Krook A, Roth RA, Jiang XJ, Zierath JR, Wallberg-Henriksson H (1998) Insulin-stimulated Akt kinase activity is reduced in skeletal muscle from NIDDM subjects. Diabetes 47:12811286

38. Choi SM, Cho HJ, Cho H, Kim KH, Kim JB, Park H (2008) Stra13/DEC1 and DEC2 inhibit sterol regulatory element binding protein-1c in a hypoxia-inducible factor-dependent mechanism. Nucleic Acids Res 36:6372-6385

39. Naya FJ, Olson E (1999) MEF2: a transcriptional target for signaling pathways controlling skeletal muscle growth and differentiation. Curr Opin Cell Biol 11:683-688

40. Kelley DE, He J, Menshikova EV, Ritov VB (2002) Dysfunction of mitochondria in human skeletal muscle in type 2 diabetes. Diabetes 51:2944-2950

41. Sun Z, Liu L, Liu N, Liu Y (2008) Muscular response and adaptation to diabetes mellitus. Front Biosci 13:4765-4794 